\title{
EFEKTIVITAS PEMANFAATAN ALUN-ALUN SEBAGAI RUANG TERBUKA PUBLIK
}

\author{
Muhammad Uliah Shafar ${ }^{*}$, Suzanna Ratih Sari ${ }^{2}$ \\ Teknik Arsitektur, Universitas Diponegoro \\ e-mail: *1777uliahshafar@students.undip.ac.id,2ratihsaris@yahoo.com
}

\begin{abstract}
Abstrak_Ruang terbuka publik memiliki efek yang sangat besar terhadap kesejahteraan masyarakat perkotaan. Tujuan dari penelitian ini adalah menghasilkan rekomendasi desain untuk membangun kembali fasilitas alun -alun menjadi lebih baik, dalam hal memberikan dampak positif terhadap kesejahteraan. Karena meningkatnya kebutuhan masyarakat terhadap ruang publik, alun-alun Andi Makkasau yang berada di kota Parepare mengalami perubahan yang signifikan dalam mengakomodasi aktivitas penggunanya. Beberapa fasilitas ditambahkan seperti alat kebugaran, tempat duduk komunal, panggung utama, panggung musik dan toilet. Membuat alun-alun ini menyediakan pemanfaatan yang beragam. Namun, ketersediaan pemanfaatan tersebut tidak mengungkap efektivitas yang ada pada ruang tersebut. Renovasi alun-alun Andi Makkasau diharapkan memperhatikan dampak dari perubahan pengaturan fasilitas-fasilitas yang tersedia. Dengan menggunakan metode behavioral mapping, penelitian ini dapat menjelaskan hubungan antara pengguna dan fasilitas sebuah ruang publik. Melalui hasil sketsa dan simbol dari hasil observasi yang dilakukan pada pagi hari dan sore hari dengan menggunakan metode placecenter map, diketahui respon dari perilaku pengguna terhadap fasilitas yang digunakan di alun-alun Andi Makkasau. Adapun metode yang digunakan untuk menganalisisperforma fasilitas, penelitian ini menggunakan evaluasi purnahuni (EPH). Hasil penelitian menunjukkan bahwa renovasi alun-alun ini tidak mendukung atribut sebagian besar penggunanya, sehingga rekomendasi terhadap rancangan kedepannya sangat diperlukan.
\end{abstract}

Kata kunci: Behavioral Mapping; Ruang Terbuka Publik; Place Centre Map; Fasilitas Publik.

\begin{abstract}
Public open space has a significant effect on the welfare of urban communities. The objective of this study was to produce design recommendations for rebuilding the square facilities for the better, in terms of having a positive impact on welfare. Due to the increasing public need for public space, the Andi Makkasau square in the city of Parepare has undergone significant changes in accommodating the activities of its users. Some facilities were added, such as fitness equipment, communal seating, main stage, music stage, and toilet. As a result, this square provided multiple uses. However, the availability of these uses did not reveal the effectiveness of that space. The renovation of Andi Makkasau square was expected to pay attention to changes in the arrangement of available facilities. By using the behavioral mapping method, this study could explain the relationship between users and facilities of open space. Through the sketches and symbols from the observations made in the morning and evening using the place center map method, user behavior was known to the facilities used in the Andi Makkasau square. The method used to analyze the facility's performance; this study used the post-occupancy evaluation (POE). The results showed that the renovation of this plaza did not support the attributes of most of its users, so recommendations for future designs were needed.
\end{abstract}

Keywords: Behavioral Mapping; Public Open Space; Place Centre Map; Public Facilities.

\footnotetext{
${ }^{1}$ Jurusan Arsitektur Fakultas Teknik Universitas Diponegoro
}

${ }^{2}$ Jurusan Arsitektur Fakultas Teknik Universitas Diponegoro 


\section{PENDAHULUAN}

Keberadaan ruang terbuka publikmerupakan satu diantara elemen utamaperkotaan yang harus diperhatikan. Peningkatan efektivitas sebuah ruang terbuka publik memiliki makna peningkatan kualitas sebuah kota yang didalamnya diisi oleh masyarakat yang bergantung terhadap lingkungan mereka. Ruang terbukapublik menyediakansebuah fasilitas yang baik dan lengkap untuk mewadahi kebutuhan seluruh elemen pengguna.Fasilitasdalam ruang publik adalah fasilitas publik yang biasanya berada di dalam ruang publik, yaitu ruang yang dapat mewadahi kepentingan publik atau masyarakat umum(Darmawan,2005). Kepentingan tersebut di antaranya: melakukan komunikasi dengan kolega, pertemuan informal komunitas tertentu, bermain, jalanjalan, melihat-lihat taman dan penghijauan, sekedar melihat orang lewat atau memperhatikan kegiatan orang di sekitar ruang tersebut.

Lapangan Andi Makkasau terletak di tengah kota Parepare. Lokasinya yang sangat strategis menjadi pilihan warga sekitar untuk menghabiskan waktu di luar ruangan. Keunggulan tersebut membuat lapangan ini digemari oleh banyak orang untuk berolahraga. Pada saat ini, terdapat penambahan fasilitas baru ditempat ini. Beberapa fasilitas yang ditambahkan adalah alat kebugaran, tempat duduk komunal, panggung utama, panggung musik dan WC/toilet. Selain penambahan fasilitas, aktivitas dikawasan ini juga mengalami peningkatan. Saat ini masyarakat tidak hanya menggunakan lapangan untuk berolahraga akan tetapi juga digunakan sebagai tempat rekreasi dan berdagang untuk meningkatkan pendapatan dan kesejahteraan.

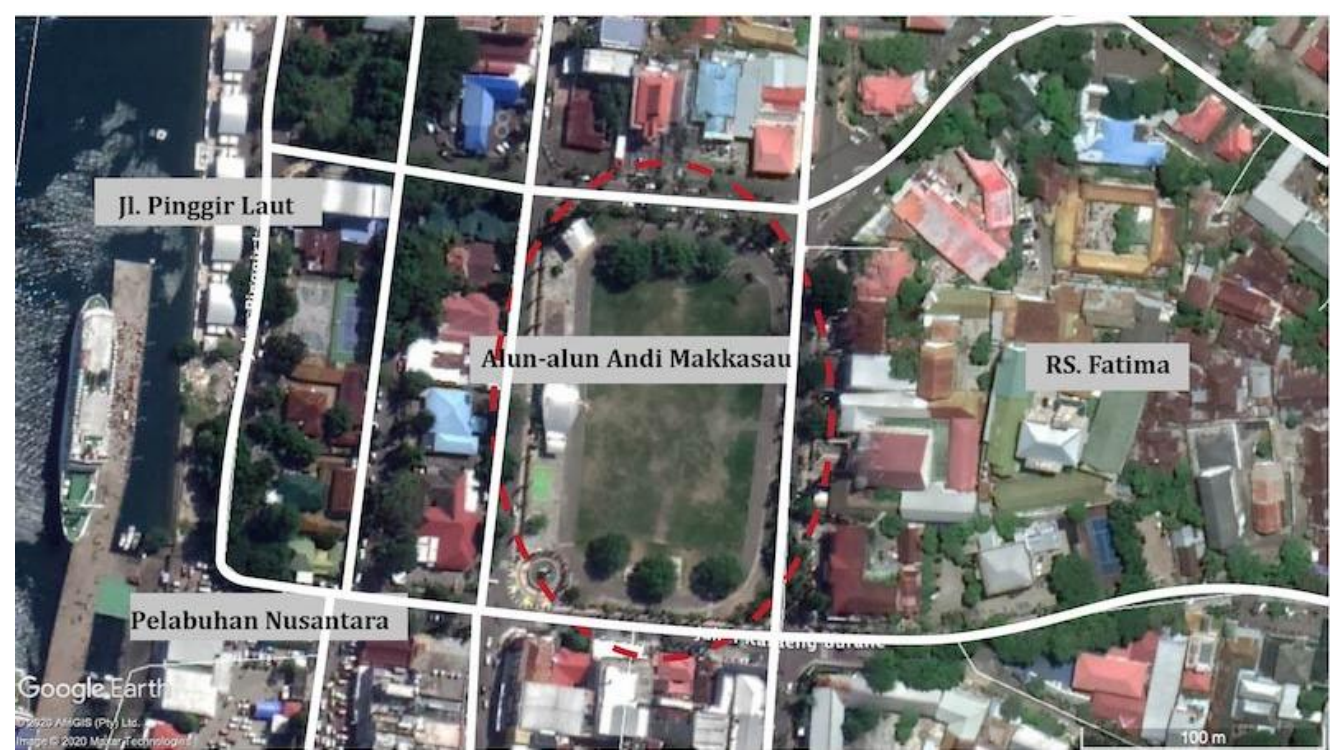

Gambar 1. Lokasi dari Alun-Alun Andi Makkasau, Parepare

Peningkatan jumlah prasarana tersebut mengubah wajah lapangan Andi Makkasau yang sebelumnya sekedar lapangan olahraga kemudian berubahmenjadi ruang terbuka publik untuk semua kalangan warga kota Parepare. Perubahan fungsi itu memiliki alasan yang jelas yaitu adanya pertumbuhan penduduk dalam sebuah kota. Hal ini mengakibatkan permintaan terhadap fasilitas penunjang meningkat seperti peningkatan kebutuhan terhadap ruang terbuka publik. Menurut Kelly (Fajar etal., 2008) sebagai sarana rekreasi, ruang terbuka publik merupakan tempat untuk melakukan aktivitas rekreasi bagi pelakunya. Rekreasi merupakan salah satu yang dibutuhkan 
manusia,karena dengan rekreasi diharapkan pelaku dapatmenyegarkanindividu seutuhnya baik badan, pikiran, dan semangat. Perubahan Alun-alun Andi Makkasau ini membuat elemenelemennya harus beradaptasi terhadap kebutuhan dari fungsi saat ini. Sehingga setiap pengguna dapat merasakan manfaat fasilitas yang ada tanpa terganggu oleh fasilitas yang telah ada sebelumnya.

Pemerintah kota Parepare telah melakukan penambahan fasilitas publik. Penyediaan fasilitas publik ini tidak berarti secara langsung memenuhi tujuan perencanaan atau kriteria ruang publik yang berkualitas. Oleh karena fasilitas publik ada yang tidak berfungsi dengan efektif dan efisien, maka fasilitas-fasilitas tersebut kurang digunakan dan mempengaruhi tingkat efektivitas fasilitas publik Andi Makkasau. Menurut Muharam (2002) ruang publik berperan sangat penting dalam kehidupan masyarakat urban, selain itu mempunyai pengaruh terhadap pola perilaku pengguna khususnya menyangkut lingkungan tempat ia berada. Untuk mengetahui efektivitas fasilitas publik tersebut diperlukan analisis terhadap hubungan antara perilaku pengguna dengan fasilitas yang mengakomodasi aktivitas mereka. Untuk menilai hubungan antara pengguna dan lingkungan, dilihat dari pemanfaatannya dalam pembentukan karakter visual dan mempunyai fungsi interaksi sosial didalamnya (Kusumaning, 2018).

Fasilitas publik di alun-alun Andi Makkasau memiliki tingkat penggunaan yang berbeda. Kebanyakan pengguna menggunakan fasilitas olahraga dibanding fasilitas rekreasi. Padahal pengguna ruang publik tidak hanya berharap kepada fungsi olahraganya saja, melainkan fungsi sosial, ekonomi, dan lain-lain. Perilaku pengguna dalam memanfaatkan fasilitas sangat beragam. Ada yang memanfaatkannya dikarenakan aspek ketenanganprivasi yang ditawarkan, kebersihan, dan keindahan yang dimiliki fasilitas tersebut. Apabila pengguna merasa kurang terhadap kualitas dari suatu fasilitas, orang akan cenderung menempati fasilitas yang lain bahkan yang tidak diperuntukkan fungsinya yang menyebabkan beberapa fasilitas memiliki fungsi ganda dan tidak terpakai.

Berdasarkan hasil pembahasan DPRD (Dewan Perwakilan Rakyat Daerah), kecenderungan pada jenis penggunaan di alun-alun menitikberatkan terhadap fasilitas olahraga.Menurut Alam selaku wakil ketua DPRD (Anwar, 2017), tempat duduk pada alun-alun sudah memadai dan tidak perlu dibuat lagi. Walaupun terdapat banyak tempat duduk, fasilitas tersebut tidak optimal terhadap kebutuhan penggunanya. Melalui gambaran hubungan antara perilaku dan lingkungan bagi perancangan arsitektur, fasilitas yang kurang efektif dapat diperbaiki sesuai dengan kebutuhan yang sesuai dengan masing-masing pengguna.

\section{METODE}

Metode penelitian yang digunakan adalah metode penelitian kualitatif deskriptif. Metode ini berfokus pada berbagai aktivitas pengguna dalam memanfaatkan macam-macam fasilitas yang tersedia baik yang telah lama maupun yang baru. Kegiatan hasil observasi lapangan didokumentasikan melaluisketsa pemetaan perilaku untuk menggambarkan suatu unit hubungan antara perilaku dan lingkungan bagi perancangan arsitektur (Laurens, 2004). Objek penelitian ini adalah pengguna alun-alun Andi Makkasau pada pagi dan sore hari. 


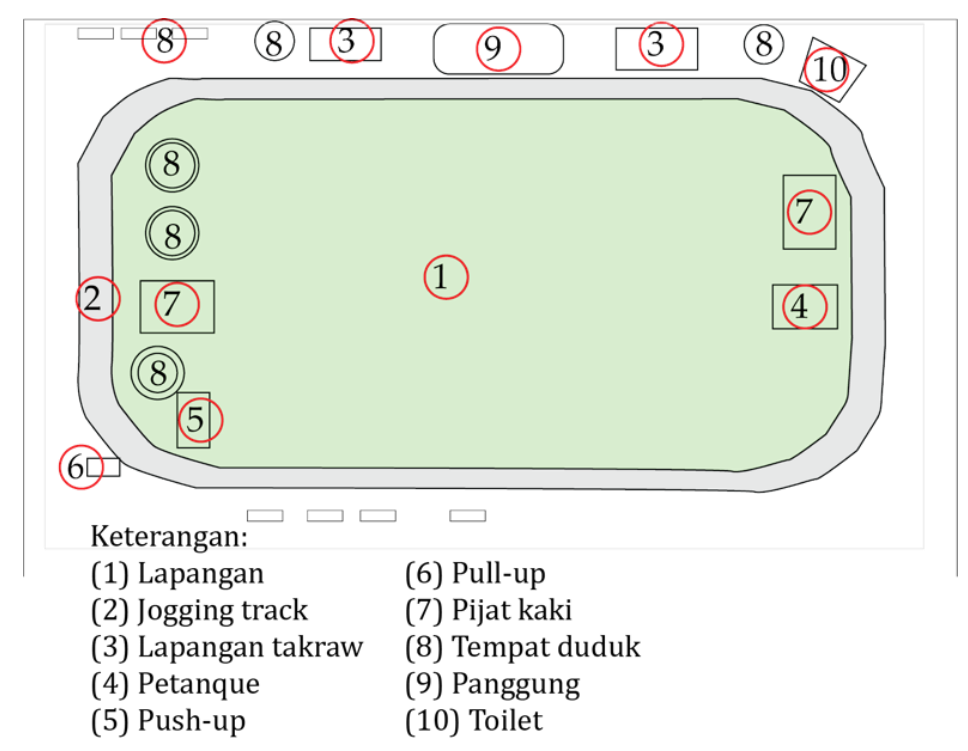

Gambar 2. Sketsa Sederhana

Metode yang digunakan untuk menganalisis performa ruang publik adalah evaluasi purnahuni. Tujuan evaluasipurna huni adalah meneliti efek dari sebuah bangunan terhadap penggunanya. Stakeholder dapat memanfaatkan pemahaman yang lebih baik terhadap interaksi pengguna.Evaluasi purna huni dalam kasus ini melibatkan langkah-langkah menyeluruh dan tepat, termasuk analisis faktor (Federal Facilities Council, 2001). Menurut Preiseretal (2015) evaluasi purna huni berfokus kepada aspek-aspek evaluasi teknis, fungsi dan perilaku. Dalam proses analisisnya, metode EPH ini dapat dilakukan dalam jangka pendek, menengah, dan panjang tergantung dari seberapa luas dan seberapa detail permasalahan ruang publik tersebut (Kusumastuty, 2016).

\section{HASIL DAN PEMBAHASAN}

Pada pengamatan pertama, Peneliti membagi dua bagian waktu pengamatan, yaitu pada pagi hari dan sore hari dengan menggunakan pemetaan placed-center mapping. Berdasarkan pemetaan menggunakan placed-center mapping, diketahui bahwa mayoritas pemanfaatan fasilitas ruang publik adalah jogging track.

Dilihat pada gambar 3 aktivitas alun-alun hasil pemetaan perilaku berpusat pada kegiatan lari-lari atau jogging. Sementara, aktivitas ekonomi berkumpul pada pintu keluar sebelah utara di bahu jalan raya alun-alun Andi Makkasau. Jumlah pedagang tidak menunjukkan jumlah yang signifikan pada waktu pengamatan. 


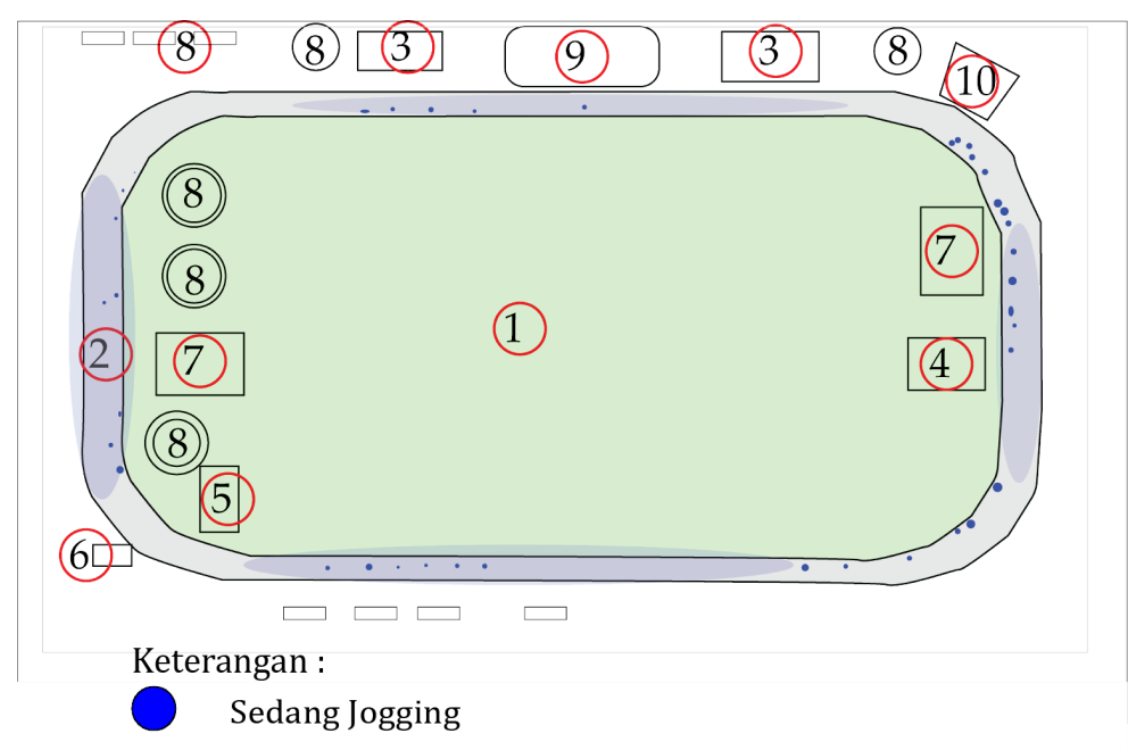

Gambar 3. Pemetaan Perilaku Jogging Track

Aktivitas diluar jogging track terdapat aktivitas fisik yang merupakan tempat mayoritas pengunjung berada. Aktivitas fisik ini terdiri dari tempat push-up, tempat pull-up, lapangan bola takraw dan lapangan olahraga petanque. Dapat dilihat pada gambar 4 bahwa selain tempat aktivitas fisik, menunjukkan kurangnya minat dalam menggunakan fasilitas seperti tempat pijat kaki(yang ditunjukkan oleh nomor7 pada gambar dibawah) dan tempat duduk(yang ditunjukkan oleh nomor8 pada gambardibawah) yang baru dibangun.

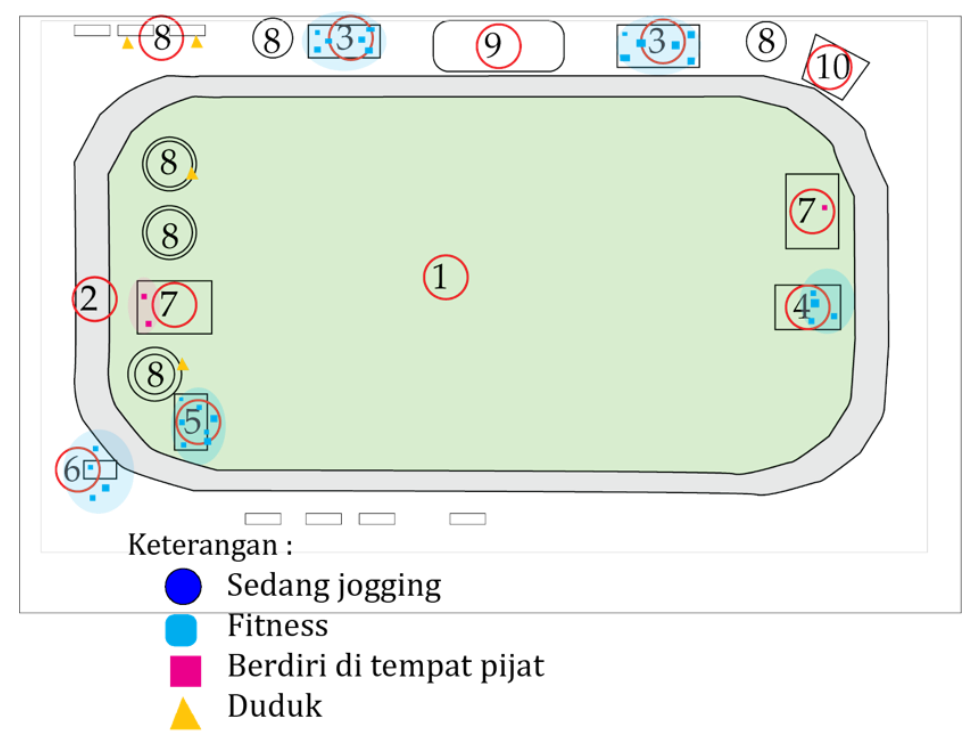

Gambar 4. Pemetaan Perilaku Tempat Duduk

Toilet (yang ditunjukkan oleh nomor 10 pada gambar di atas) yang disertai panggung musik yang berada di sudut utara alun-alun Andi Makkasau memiliki intensitas penggunaan yang kurang. Selain itu, jumlah toilet yang hanya ada satu dan berjauhan terhadap fasilitas lainnya membuat 
pengguna harus berjalan jauh untuk menggunakan toilet. Oleh sebab itu tempat ini tidak bekerja sebagaimana mestinya. Dengan demikian, sebaiknya toilet tersebut diperbaiki dengan memperhatikan hubungan kedekatan ruang.

\section{A. Evaluasi Fungsi}

Ada beberapa fasilitas di alun-alun Andi Makkasau tidak digunakan dengan baik. Alasan diantaranya adalah karena desain yang kurang mempertimbangkan pemanfaatan dan menurunnya daya tahan fasilitas tersebutkebanyakan disebabkan oleh gelandangan. Agar dapat memperbaikinya, sebaiknya ada desain fasilitas untuk menghindari kemungkinan terjadinya malfungsi fasilitas serta desain fasilitas mengikuti fungsi dan kebutuhan pengguna. Sebagai contoh, tempat duduk sebaiknya tidak dimanfaatkan oleh gelandangan untuk tidur. Selain itu, sebaiknya toilet ditempatkan didekat keramaian agar dapat terjangkau oleh semua pengguna.

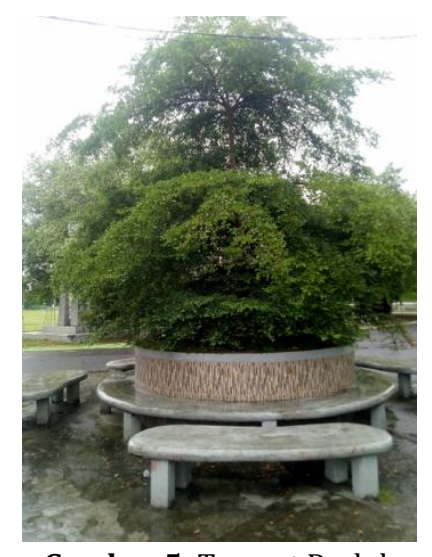

Gambar 5. Tempat Duduk

Salah satu yang menjadi perhatian adalah kursi komunal yang baru dibangun di Alun-alun ini. Tempat ini seharusnya menjadi lokasi terpenting dalam ruang publik dengan tujuan mewadahi interaksi sosial masyarakat. Mudahnya kotordan tidak memenuhi atribut pengguna membuat tempat tersebut tidak berjalanan dengan baik. Adanya kotoran yang menempel di kursi seringkali mengusik kenyamanan pengguna. Selain itu, atribut pengguna yang tidak terpenuhi adalah kurangnya privasi dalam penggunaannya.

Privasi adalah kemampuan seseorang atau sekelompok orang untuk mengendalikan interaksi mereka dengan orang lain baik secara visual dan audial untuk mendapatkan apa yang diinginkannya (Rapoport, 1977). Seperti yang dilihat gambar 5, menunjukkan tidak adanya batasan-batasan tersebut. Jarak antarpengguna sangat dekat bahkan tidak melebihi 3 meter. Menurut Hall (Puspita etal.,2013), jarak public fase dekat adalah 3,65-7,62 meter dan fase jauh adalah lebih dari 7,62 meter.

Pada panggung musik yang disertai toilet, fungsi pada panggung ini terkesan tidak terpakai disebabkan oleh kedekatannya dengan panggung utama yang memudarkan fungsinya.Toilet yang berada di panggung musik tersebut juga seringkali terkunci dikarenakan pengelolahannya yang rumit. Beberapa interview mengatakan aksesibilitas dari seluruh lapangan juga sulit. Orang yang berada di sisi lain alun-alun akan merasa kejauhan untuk menuju $W C$ tersebut. 


\section{B. Evaluasi Teknis}

Masalah teknis yang termasuk dalam pengamatan penelitian adalah tempat duduk yang tidak memiliki fitur sandar antangan. Beberapa kasus tempat duduk yang ada di ruang publik dan tidak memiliki fitur tersebut akan sering ditempati gelandangan untuk beraktivitas disaat sepi terutama di malam hari. Hal tersebut akan mengakibatkan kekotoran pada tempat duduk.

Aksesibilitas $W C$ merupakan hal utama yang dikeluhkan oleh pengguna. Selain lokasinya yang tidak strategis, $W C$ ini juga mengharuskan pengguna untuk turun tangga agar dapat menggunakan $W C$ ini. Hal ini menyusahkan beberapa unsur masyarakat yang memiliki keterbatasan fisik yang sewajarnya menggunakan ramp untu kaksesvertikal.

\section{Evaluasi Perilaku}

Berdasarkan hasil pengamatan behavioralsetting, masyarakat masih senang menggunakan kursi yang lama. Penempatan tempat duduk tersebut disebar di pinggiranpinggiran Alun-alun seperti pada gambar 6. Meskipun kursi lama tersebut telah memiliki dudukan yang sedikit lapuk, tetapi masih cukup untuk menunjang atribut privasi dan kenyamanan beberapa orang. Adapun kekurangannya adalah masih minimnya kursi itu dibanding jumlah pengguna Alun-alun.

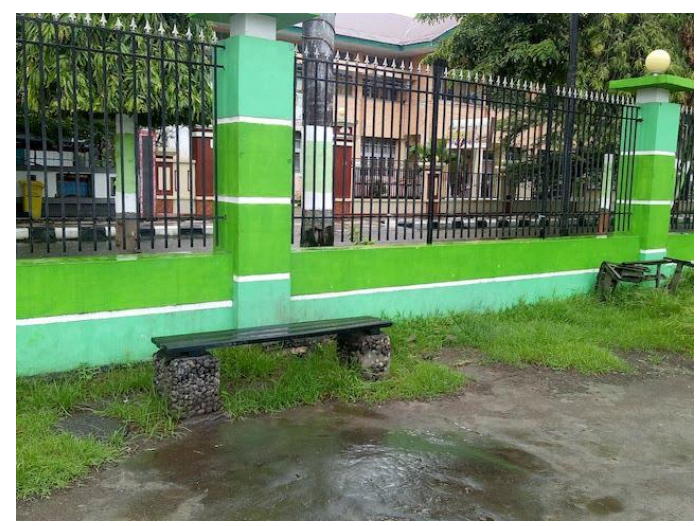

Gambar 6, Tempat Duduk

Hal lain yang berkaitan dengan evaluasi perilaku adalah bahwa sebagian besar pengguna alun-alun berada di fasilitas-fasilitas olahraga. Seperti jogging track, lapangan bola, pull-up bar dan push-up bar. Hal ini menjelaskan bahwa masyarakat lebih tertarik pada aktivitas olahraga di pagi dan sore hari. Fasilitas-fasilitas olahraga sebaiknya diutamakan dibandingkan dengan fasilitas interaksi sosial dan lain-lain.

Setelah meninjau hasil dan pembahasan, penulis memberikan rancangan rekomendasi untuk beberapa permasalahan. Adapun permasalahan tersebut yaitu rancangan tempat duduk komunal dan rancangan toilet. Sementara itu mempertahankan fasilitas-fasilitas yang telah memberikan pemanfaatan yang baik untuk alun-alun. 


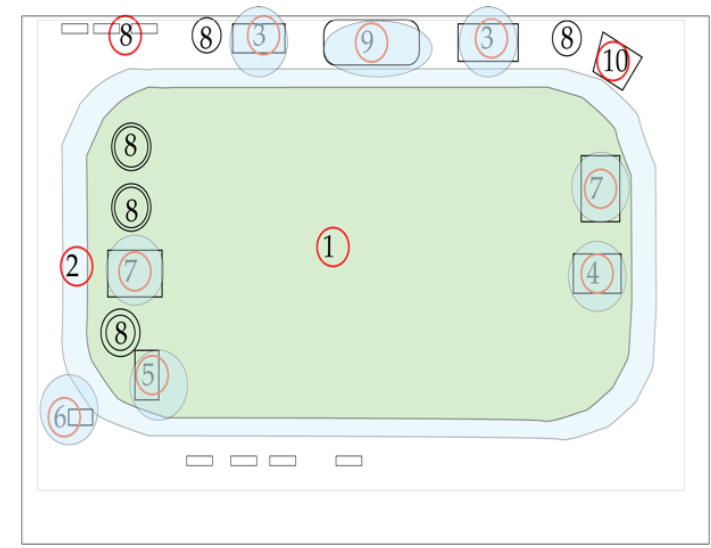

(a) Fasilitas yang tidak direnovasi

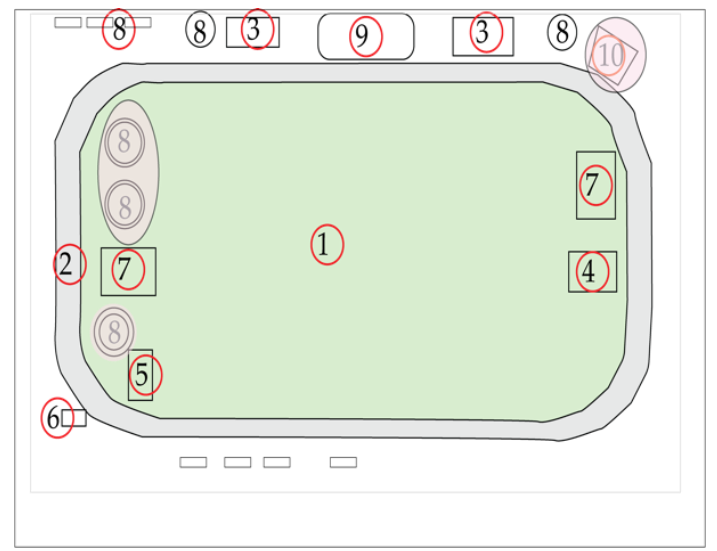

(b) Fasilitas yang direncanakan direnovasi

Gambar 7. Kondisi Perencanaan Fasilitas yang Berubah dan Tidak Berubah

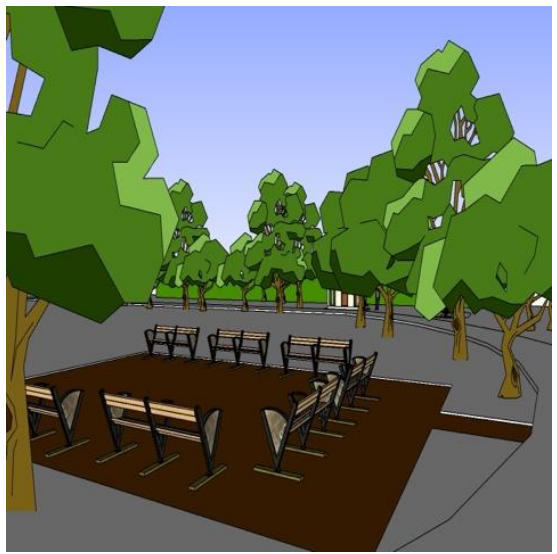

(a) Konsep tempat duduk

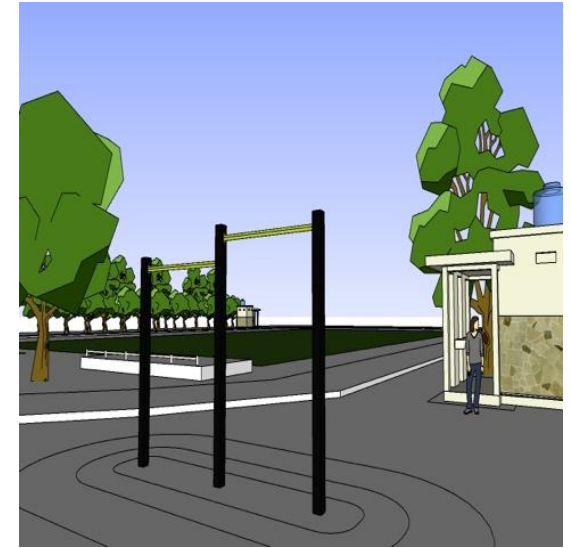

(b) Konsep toilet sederhana

Gambar 8. Konsep Desain

Pada gambar 8a merespon terhadap kekurangan fasilitas tempat duduk yang baru, sedangkan gambar 8b merespon terhadap penempatan $W C$ yaitu dengan menambahkan 1 WC di sisi lain alun-alun.

\section{KESIMPULAN}

Pada kenyataannya alun-alun Andi Makkasau masih kurang dalam tingkat efektifitas ruang publik. Dalam pengamatan menggunakan pemetaan place-centered, hubungan perilaku dan fasilitas yang mengakomodasi memiliki celah yang besar. Untuk itu diperlukan desain yang dapat mendukung atribut yang dijelaskan dalam pembahasan tentang perilaku pengguna. Melalui pengamatan tadi, menghasilkan beberapa fasilitas yang masih butuh perbaikan. Setelah melakukan evaluasi purna huni(EPH), untuk fungsi olahraga masih memerlukan penambahan fasilitas, sedangkan fungsi lainnya sudah cukup namun perlu diadakan perbaikan untuk materialnya. 


\section{DAFTAR REFERENSI}

Anwar, A. (2017). Warga Butuh Alat Olahraga, Pemkot Malah Bangun Tempat Duduk.

AS, Zulkarnain. "Wujud Arsitektural Rumah Tradisional Duri Asli di Kabupaten Enrekang." Nature : National Academic Journal of Architecture 2, no. 2 (2015): 130-37.

Darmawan, E. (2005). Ruang Publik dan Kualitas Ruang Kota, dalam Seminar Nasional pesat 2005. Universitas Gunadarma, Jakarta, 23-24.

Fajar, O. ., M. L2d, J. Perencanaan, W. Dan, and K. Fakultas (2008). Ketersediaan Ruang Terbuka Publik Dengan Aktivitas Rekreasi Masyarakat Penghuni Perumnas Banyumanik Tugas Akhir.

Federal FacilitiesCouncil (2001). LearningFrom Our Buildings. Washington, DC: National Academy Press.

Kusumaning Wardhani, M. (2018). Titik Nol Kilometer Kota Yogyakarta Sebagai Ruang Terbuka Publik Ditinjau Dari Dimensi Fungsional, Sosial, dan Visual. Jurnal Planologi 15(1), 1.

Kusumastuty, K. D. (2016). Prospek Analisis PostOccupancyEvaluation (POE) sebagai Tinjauan untuk Mengevaluasi Performa Ruang Terbuka Hijau Publik di Perkotaan. Prosiding Temu Ilmiah IPLBI 2016.

Laurens, J. M. (2004). Arsitektur dan perilaku manusia. Penerbit PT Grasindo.

Muharam, A. (2002). Citra dan Identitas Kawasan: Konsep Desain Elemen Fisik Kawasan Pedestrian Dago. Program Magister Desain-Institut Teknologi Bandung.

Preiser, W. F. E., E. White, and H. Rabinowitz (2015). Post-OccupancyEvaluation (RoutledgeRevivals). Routledge.

Puspita, A. A., D. Wiyancoko, and D. Saphiranti (2013). Kajian terhadap Sarana Duduk Publik Kampus dengan Pendekatan Perilaku dan Aktivitas Warga Kampus (Studi Kasus pada Kampus Institut Teknologi Bandung Ganesha). Journalof Visual Art and Design 5(1), 1-19.

Rapoport, A. (1977). Human aspectsof Urban Form: Towards A Man-Environmentapproachto Urban Formanddesign. Elsevier. 